\title{
MODOS DE VER EL PENSAMIENTO
}

\author{
Anibal Alemán y Freddy Quezada
}

\begin{abstract}
Resumen:
El presente artículo está estructurado en cuatro partes. En primera instancia se aborda lo que el pensamiento presupone, donde se destaca las cinco cosas comunes que el pensamiento dice de sí mismo, que son: está en la cabeza, está antes toda acción, está por encima de cualquier otra cosa, pensar, primero fue olvidar diferencias y, abora, recordarlas y la que no se dice: el pensamiento no es la fuente de todas las soluciones, sino, el principal problema de ellas. Posteriormente se explica de lo que el pensamiento se compone con la ilustración del tetralema de Nagarjuna, seguidamente se presenta a los que el pensamiento se impone, con criterios, por parte de los pensadores de las ex-colonias, con tres alternativas: como copia, como bibridez y como un pensamiento "otro". Por último se encuentra a quienes, el pensamiento, (in) dispone, donde nos proponemos tres cosas con relación al pensamiento.
\end{abstract}

Palabras clave: Pensamiento, pensamiento problema, ex-colonia, receptores de pensamiento.

\begin{abstract}
:
This essay is structured in four parts. The former one bighlights the five common aspects that thinking sets itself: belong from bead, before any action, above anything else; think, former was forget differences, now remember them, and at the end: thinking is not the source of solutions, but also, the main problem of its. Forwards explain what thought consists through Nagarjuna Tetralemma illustration. After that mentioned those who thought prevails, criteria of the thinkers of the ex-colonies with three alternatives: as a copy, as a bybridity, as a though "other". Finally, find who bas thought, explaining three aspects related to thought.
\end{abstract}

Keywords: Thought, thinking problem, ex-colonies, recipients of thought.

\section{Introducción}

El título, parte de que hay un observador externo a los modos de ver el pensamiento (que en puridad habría que presentar también en plural), observador que sería, a su vez, un invento del pensamiento mismo, y "ver" que sería un atributo necesario, pero no suficiente, para rendir cuentas de un fenómeno como "el pensamiento".

¿Puede verse el ojo a sí mismo, en un espejo, por ejemplo o, lo que mira, incluso desde ahí, es sólo su pasado? No es que los viejos modos de pensar se nieguen a morir y los nuevos no terminen de nacer, sino que su combinación alucinante, hoy, nos impide separarlos o, por lo menos, nos exige un esfuerzo supremo para tratar de distinguirlos.

\section{El ensayo está estructurado en cuatro partes sencillas:}

a) cómo se mira el pensamiento a sí mismo y nos convence de ello.

b) cómo componen, sus distintas variedades, su sentido y lógica.

c) cómo se impuso a los subalternos de "dentro" (necios) y de "fuera" (ex-colonias) y cómo fue recibido por ellos.

d) en quiénes se "reconcilia" (i?) todo.

\section{Lo que el pensamiento presupone}

Las cinco cosas comunes que el pensamiento dice de sí mismo son:

\section{Está en la cabeza}

La idea de que el pensamiento está en la cabeza, nos llega de una discusión doble, en la que intervienen la ciencia, por un lado y la sabiduría, por el otro. En primer lugar, la idea que no sólo el cerebro piensa, sino cada una de nuestras células en una especie de holograma, ha sido probada y, la segunda, el litigio que establecen neurofisiólogos y filósofos, sobre la relación que se establece entre la mente y el cerebro.

A menudo se dice que el sexto sentido es el pensamiento que, de administrar a los otros cinco, terminó por expropiarlos. Y no deja de llevar razón por el tratamiento que ha terminado propinándoles. Incluso Heidegger, hizo de su cueva -- la diferencia entre lo "a la mano" (zuhandenheit) y lo "a la vista" (vorhandenheit), siendo aquello la base de los entes y ésta la de la metafísica -- su trampa. El archivo y las sensaciones que se guardan ha sido también trabajado por autores radicales, como U.G. Krishnamurti, quienes 
señalan que el cerebro sólo sirve para afinar las sensaciones y, la mente, un archivo inútil que sólo sabe mirar el pasado.

\section{Está antes de toda acción}

Nada es digno de pensarse si los efectos de cualquier causa al expresarse en los hechos, no se ofrecieran a la reflexión en sus dos caras como afirmación y como crítica. La acción, la realidad, siempre viene después del pensamiento y sólo interesa averiguar sus puntos de partida en un fundamento o archeos y en un destino, telos, cuyas nostalgias y marchas se representan como lineales, dialécticas o sistémicas.

El grueso de su despliegue como práctica no interesa más que como el escenario donde la doxa recibe las órdenes de los dioses y sus libros sagrados o de sus sucedáneos, los pensadores. El principio que quiebra este prejuicio, es aquel que nos dice que el pensamiento ya es acción.

\section{Está por encima de cualquier otra cosa}

No son modelos religiosos, científicos, económicos o culturales los que están más allá del bien y mal, sino el pensamiento mismo. Lo único que se nos ha hecho creer que está por encima del pensamiento, son los dioses que, paradoja, él mismo inventó por medio de la escritura y de quienes la llegaron a dominar con maestría: los pensadores. Pero, el pensamiento, en verdad, no puede estar por encima de la vida de la que es su fruto, para bien o para mal.

\section{Pensar, primero, fue olvidar diferencias y ahora, recordarlas.}

El movimiento del pensamiento, sin que se quiera decir que ha sido simple, se ha movido pendularmente entre separar y reunir, volver a separar y, de nuevo, reconciliar las cosas y seres. Todo acto de separación produce un observador $y$, todo de reunión, a un salvador. Tal es la historia del pensamiento moderno occidental (el crítico y el emancipador; el científico y el profeta; el pensador y la solución). El mismo principio gobierna otra de sus versiones que son la homogeneización y la diferencia. Aquella necesitó, hasta hace muy poco, borrar las diferencias para convencernos de su unidad y eternidad, borrando tiempo y espacio; a ese orden pertenecen las categorías metafísicas maestras (trabajo, espíritu, ser, lenguaje, diferencia, deconstrucción, etc) que caracterizan a casi todos los pensadores.

Es célebre la expresión de Borges que "pensar es olvidar diferencias", más espectacular, aún, fue la inversión que hizo de ella Heidegger, al fundar el pensamiento en la diferencia entre ser y entes. Y la que continuaría
Foucault, al dotarlo de discontinuidades y acopio de archivos al servicio de poderes y resistencias.

\section{La que no dice}

El pensamiento no es la fuente de todas las soluciones, sino, el principal problema de ellas. Puesta en negativo, como la miran J. Krishnamurti y Osho, entre otros pensadores no occidentales, quizás este sea el registro en el que tienen que desembocar las cuatro premisas anteriores: el pensamiento consiste en resolver problemas. Ningún problema se resuelve solo o deja disolverse. Para solucionarlo, el pensamiento moderno, al menos, necesita el concurso y la observación de un sujeto que ejerza su dominio sobre lo que le ofrecerá, de entrada, resistencias y opacidad.

De todas estas cosas, pensadores o no, partimos como certezas apodícticas o como sentido común para vertebrar sistemas teóricos y llamados a la acción. Pasemos a ver ahora su constitución interna y la colonia de reglas que regulan el pensamiento en sus distintos paradigmas.

\section{De lo que el pensamiento se compone}

El pensamiento es la primera de todas las religiones. Y la prueba que el pensamiento es una religión, consiste en ser el dios de los ateos, de una parte de los científicos y de la mayoría de los filósofos. La que creó a todas las demás y se separó calladamente de ellas. Bastó que alguien supiera dominar las artes de la comunicación oral y escrita para derivar de ellas todo el poder de dioses y libros sagrados, confrados a ellos como intérpretes autorizados.

Por otro lado, la relación entre occidente y oriente que plantea Said (2008:68) en su obra "Orientalismo" es una relación de poder y de complicada dominación: Occidente ha ejercido diferentes grados de hegemonía sobre "Oriente", con la expresión de varios términos, como se presenta en la siguiente tabla:

\begin{tabular}{|c|c|}
\hline Oriental & Occidente \\
\hline Irracional & Racional \\
\hline Depravado & Virtuoso \\
\hline Infantil & Maduro \\
\hline Diferente & Normal \\
\hline
\end{tabular}

Fuente: Said (2008:68). Cuadro de elaboración nuestra. 
Es evidente la discriminación epistemológica, por parte de occidente, que se muestra como un juez en un tribunal, que solo está para juzgar. Desde este panorama se puede visualizar un ideal en el pensamiento, que ha dominado el mundo, sin importar la crisis financiera mundial que impacta de manera severa al sistema capitalista.

De Heidegger en adelante se ha distinguido el pensamiento que calcula del que reflexiona. Aquel (rechnende Denken), se basa en un sujeto que se adecúa a un objeto (operación que va desde la metafísica de Platón hasta la tecnología actual, pasando por la ciencia) a través del cual se buscan resultados. Este (besinnliche Denken), en cambio, no busca nada y se manifiesta de modo gratuito, se da (es gibt). Y ese darse, como las rosas que florecen porque sí, se cumple en cualquier suceso del que se apropia (ereignis) el Ser. Quizás sea el propio Borges, quien lo haya resumido con su maestría de siempre: "las cosas sólo suceden".

Se puede ver, el pensamiento, pues, desde dentro', como reglas que, por brevedad y siguiendo a un pensador no occidental (Nagarjuna), para tratar de verlas desde otra mirada y otra forma de agruparlas, quien le llama tetralema, podemos presentar así:

Todo es (la metafísica de las certezas y fundamentos que va desde Parménides/Platón, pasando por Descartes, Kant y otros, hasta pensadores, postmodernos incluso, de todo tipo). Se basa en certezas apodícticas y en fundamentos que le llegan de poder afirmarlas a través de la escritura ${ }^{2}$, que permite su despliegue a quienes se vuelven profesionales de ella.

Todo no es (la apofática y la dialéctica negativa que va desde la escuela de Frankfurt, pasando por Heideger y parcialmente Nietzsche, hasta los postcoloniales). Se basa en prohibirse afirmaciones y derivar, por lo que no se dice, una verdad que se manifiesta rehusándose.

Todo es y no es (la dialéctica clásica que va desde Heráclito hasta Hegel pasando por Marx y todo tipo de revolucionario). Representa un espíritu único, en su origen, que se escinde dolorosamente, produciendo la historia, sólo para volverse a reconciliar, al final, consigo mismo y, en el tiempo entre uno y otro, reconocer la ambigüedad, que faculta al representante a hablar por los dos aspectos de lo real.
Todo ni es ni no es (el escepticismo, el nihilismo, la codeterminación de un polo por el otro, como lo vio Derrida $^{3}$ y viceversa; y el principio del vacío, sunyata). Se basa en un vacío sostenedor de una red correlativa, donde unos nudos se generan por los demás y, todos juntos, a su vez, se remiten unos a otros, condenados a deshacerse, sin anclajes monoteístas, ni categorías maestras centrales. El vacío también está sujeto a las mismas reglas que crea, de tal modo que, a diferencia de la deconstrucción, que se guarda de su objeto, él mismo se empuja a desaparecer.

\section{A los que el pensamiento se impone}

En primer lugar se impuso a los cuerpos a quienes convirtió literalmente en esclavos. Y hay que señalar que los cuerpos, en virtud de la misma diferencia que nos cubre hoy como fundamento, más que nadie, han sufrido tal diferencia como jerarquía. Esos cuerpos tienen colores, tamaños, sexos, edades, imperfecciones, descomposiciones y espacios que habitan. Si nos viéramos obligados a señalar a alguien que une lo que no está separado, diríamos que los verdaderos filósofos son los artesanos, pues, son los únicos que piensan con las manos. Apenas está despuntando todo ese universo ${ }^{4}$. Luego, la imposición, alcanzó a los "necios" y subalternos considerados menores de edad, bisagra conceptual popularizada por Kant, que se le hará llegar también a las colonias bajo el imperio de las potencias marítimas europeas. Hacia abajo (con los necios practicando la doxa) y hacia afuera (con colonos racializados), pues, las potencias europeas, los poderosos y los pensadores, impusieron sus reglas en medio de sus rivalidades, pero también de sus alianzas, entre escuelas y coronas.

El pensamiento se puede ver desde afuera, como una exterioridad (sin importar sus contenidos, haciendo ver que no interesa si es la filosofía continental de alemanes y franceses la superior, o no, a la analítica pragmática anglosajona); exterioridad significa aquí, una relación de poder entre los privilegiados metropolitanos del pensamiento, y quienes los recibieron, y lo siguen haciendo, en las excolonias, abriéndose el recibo del pensamiento por parte de los pensadores de las ex-colonias a tres alternativas:

Como copia. Se recibe el pensamiento metropolitano y se lo hace una copia de segunda (como lo señaló Salazar

1. Nos referiremos a todas ellas (a las clásicas cartesianas de dudar, analizar, sintetizar y evaluar; a las reglas formales de Kant; a la conciencia siempre de algo, como sentido, de Husserl; a las cadenas de superaciones dialécticas de Hegel y al pensamiento no metafísico y gratuito de Heidegger), agrupadas, de otro modo, y para hacerlo desde otra cultura, por Nagarjuna (2006), pensador budista que funda la orden Mahayana.

2. Derrida (1989) ha pasado a ser héroe y villano, a la vez, pues su procedimiento de la escritura logró reunir, en su seno, a pensadores, críticos, escritores artísticos, religiosos, cientistas sociales, publicistas y cualquier escribano a quienes los hizo depender, en sus discursos, de regímenes deconstructivos cuya rendición de cuentas sólo se le debía al paradigma mismo que no llegó, tal la diferencia con Nagarjuna, a aplicárselo a sí mismo y desaparecer.

3. Spivak (2010:412) vio la conexión entre Nagarjuna y su maestro, de un modo ingenuo."Es curioso que muchas de las denominadas etnofilosofías (como el Tao, el Zen, el Sunyata, la filosofía de Nagarjuna, las variedades del sufismo, etc) muestren afinidades con partes de la deconstrucción". Es de agradecer a Derrida, sin duda, su grito apache "no hay nada fuera del texto" y que facilitará la tarea de sus críticos de acusar a toda la postmodernidad de renunciar a las luchas sociales, haciéndose satisfacer por el empleo correcto de los términos respetuosos de la diferencia, sin asunción de compromisos prácticos de lucha. 
Bondy), y no escapa a ello, ni siquiera el marxismo que bien puede ser definido como de las carabelas.

Como hibridez desfigurada, a ojos de unos, y fecunda, a la de otros (Bahba y García Canclini). El rechazo de las hibrideces corre a cuenta de los defensores de las categorías maestras puras de la que viven literalmente los pensadores más representativos, en especial los eurocentrados.

Este piso es, por el otro lado, más creativo que el sentido de copia anterior, pero se parte de él como si la hibridez fuera un punto de llegada, y no se mira como punto de despegue que crece a partir de combinaciones de combinaciones. En este nivel se advierten dos cosas: la sepultura de cualquier observador que trate de separar las combinaciones y el acercamiento asombroso a una actitud parecida a la de la gente común y corriente.

Como un pensamiento "otro", diferente, que se pronuncia desde otro espacio (locus enuntiationis) y corre el riesgo de repetir lo que censura en el adversario, al proponer otros fundamentos con Platones y Aristóteles amerindios y afrodescendientes para una segunda liberación, esta vez epistémica (Mignolo, Dussel, Quijano).

\section{A quienes, el pensamiento, (in) dispone}

¿Qué hemos buscado decir hasta aquí y qué nos proponemos? Tres cosas:

- La imagen que el pensamiento ha brindado de sí mismo y que todos, para bien o para mal, hemos hecho nuestra.

- Imagen que no ha sido única, sino que ha sido ofrecida como conjunto de alternativas rivales entre pensadores de Francia, Alemania e Inglaterra ${ }^{6}$, sin el concurso de "necios" y colonizados.

- Las formas en que han sido recibidas por estos últimos, pueden hacernos creer, en virtud de las hibrideces que componen, que se puede crear desde la imitación, en efecto, pero también, a vernos como gente común y corriente que encierra en sí misma el todo ${ }^{7}$, del que siempre ha sido excluida y del que no necesita saberlo, porque no tiene sentido separar lo que no se puede para, después, reunir lo que, de todos modos, sería inútil. Incluso, según Henry
(2007:198), Descartes afirmó “en repetidas ocasiones, que para concebir correctamente la unión del alma y el cuerpo era necesario dejar de pensar sobre tal fenómeno, para por el contrario entregarse a él y vivirlo" ${ }^{8}$.

No vamos a terminar diciendo que hay que victimizar, como hacen los programas emancipadores, a la gente común y corriente, ni criminalizarla, como hacen los neoliberales. Ni una cosa ni la otra, como el neti neti hindú, ni esto ni aquello o, como la cuarta regla del tetralema de Nagarjuna.

Creo que se puede ver el papel de la gente "común y corriente" desmesianizado, como la talidad que de todos modos somos y que, sin saberlo, permite reunir en nuestro seno todo el espectro combinatorio y abierto de los discursos que se nos ofrecen, en proporciones desiguales, siendo la diferencia, entre unas y otras personas, una cuestión de cantidades de las mezclas que no pueden ser separadas. Tales combinaciones anulan cualquier idea de sustancia o de cambio en direcciones a voluntad y las diferencias que pueden acusar las partes son, en strictu sensu, relaciones de poder.

Después de destacar el papel de la gente común, se puede clasificar de dos maneras el pensamiento en América Latina:

1. Una forma oficial de tratar el pensamiento: aprender en la universidad "consiste en una problemática europea traducida a nivel filosófico”.(Kusch: 1996:16).

2. Una forma privada de hacer el pensamiento: Es un pensamiento no reconocido e implícito, vivido cotidianamente en la calle o en el campo.

No se trata de eliminar el pensamiento, sino de quemar la ilusión que está separado de los cuerpos de la gente común y de todo lo demás. El pensamiento es un viaje puramente ilusorio ${ }^{10}$, cuyo soporte es la separación de las cosas como observador (que no es más que el pasado almacenado como archivo, educación, cultura, monumento, memoria, museo, historia et al) y el establecimiento de un dualismo perpetuo del que hay que despertar.

4. Sloterdijk dice que la alta cultura convirtió a la artesanía en "algo anónimo y degradado" (2012:374) y Sennet (2009:9) que para los artesanos "hacer es pensar". Son, que sepamos, los únicos filósofos de relieve que les hemos visto reivindicar el papel cognitivo de los artesanos. Griegos y romanos, por otro lado, no fueron tan categóricos en la separación, como si lo serán los judeocristianos que la harán llegar hasta el cartesianismo. Henry (2007), apoyándose en Maine de Biran, y Nancy (2003), apoyándose en Deleuze, dos filósofos franceses, seguidores de Husserl y Heidegger, respectivamente, tratarán de arrancar los cuerpos, sin mucho éxito, de las mismas filosofías que abrazan para liberarlos, efectuando, al final, una vuelta de tuerca intelectual más sobre el asunto. ¿Reflexionar sobre los cuerpos no es ya traicionarlos?

5. Desde Sócrates hasta el marxismo, se les ha llamado "necios" o "masas" a la gente común y corriente, siendo este último término tan halagüeño como amenazador. Sin embargo, la alta cultura ha terminado por reconocer a regañadientes que, desde la interactividad rediática, ya no las tiene todas consigo. 
Lo único que obtiene el pensamiento al separarse de lo pensado, es volverse una técnica, como hacer hamacas. Nadie ha advertido que el pensamiento, más que las religiones y las modernidades, es el que necesita una secularización de segundo orden. Secularización que consistiría en despertarla de sus sueños de separación de sus objetos y disolverse en una realidad (talidad) sin opuestos, tal y como la mayoría de la gente común y corriente (y el budismo Zen) hace, que no andan pensando, de manera separada, en objetos reflexivos, paradigmas puros, explicaciones pacientes, especializaciones engorrosas y empleo de vocabulario pedante".

Hacer y pensar (como el carpintero y la costurera) son una y la misma cosa en ellos, es decir, en nosotros ${ }^{12}$. Empleo los dos números en plural para separar, primero, pero no para reunir después, pues nunca ha habido separación, más que como ilusión de pensadores. Así, para hablar de regreso a donde ni siquiera se ha salido, debemos encomillar, como indicamos al inicio de este trabajo, la expresión "reconciliar" las cosas y el pensamiento en las personas comunes y corrientes. No hay nada que reconciliar. Se une sólo lo separado, pero como es imposible tal separación, podemos decir que la "reconciliación", no es ni una cosa ni la otra. Es como regresar a sí mismo sin salir de sí.

El asunto nos permite describirnos, e incinerarnos en el acto, con un efecto bonzo, en el instante mismo que nos pronunciamos, sólo para anular una "reconciliación" que nadie ha solicitado, como agentes sociales separados unos de otros por los viejos dualismos platónicos. De hecho, el flujo de la vida siempre ha sido una combinación que ha venido combinándose y avanza abierta en todos sus puntos que sirven de engarce o "espera", como estructuras químicas, a todo suceso, en el que debe incluirse a un observador desapareciendo entre la gente común, de donde procede y de la que jamás ha salido, como la rosa al abrirse, sin brindar explicaciones.

Recibido: 4 de marzo, 2015

Aceptado: 25 de mayo, 2015

\section{Referencias bibliográficas}

Derrida, J (1989) La escritura y la diferencia. Barcelona: Antrophos.

Henry, M (2007) Filosofía y fenomenología del cuerpo. Salamanca: Sígueme.

Kosik, K (1967) Dialéctica de lo Concreto. México: Grijalbo. Sada, G. O.(1996) Los caminos americanos de la filosofía americana en Rodolfo Kusch/Gabriel Os valdo Sada. Buenos Aires: Fernado García Cambeiro Nagarjuna (2006) Abandono de la discusión. Madrid: Siruela. Nancy,J.L (2003) Corpus. Madrid: Arena Libros.

Sennett, R(2009) El Artesano. Barcelona: Anagrama.

Said, E(2008) Orientalismo. Barcelona: Random House Mondadori.

Sloterdijk, P (2012) Has de cambiar tu vida. Valencia: Pre-Textos. Spivak, G (2010) Crítica de la razón poscolonial. Madrid: Akal (1991) Ética de la interpretación. Barcelona: Paidós.

6. España, Portugal y, en menor medida, Holanda, fueron invisibilizadas por las trillizas y rivales, de las cuales Francia e Inglaterra fueron enemigas y aliadas, a la vez, en los océanos, permaneciendo sólo Alemania en tierra y cultivando el pensamiento que terminó por dominarlas a todas. Si eslavos, escandinavos, ibéricos y flamencos son los cinturones epistémicos pobres de las trillizas rivales, qué no dirán de los cinturones de países del Sur. ¿Los italianos? son los consigleri de las trillizas. Qué mejor representación se puede uno imaginar, como Don Vito Corleone susurrando a Cardenales, que George Steiner, que reúne en sí mismo a las trillizas, y Umberto Eco que lo aconseja. Los pensadores de EEUU, por su parte, suelen ser citados por las trillizas por el papel de potencia que tiene, pero a la cual siempre se la ha considerado, en voz baja, con desprecio. Las mismas razones, pues, que explican por qué los eurocéntricos citan a pensadores gringos son las mismas para hacerlo nosotros con ellos: por su poder. Tales trillizas rivales, y sus parientes pobres, ahora son juzgadas con la misma historia que impusieron a "necios" y colonizados y nos la hicieron padecer.

7. Llamamos único e irrepetible a la mezcla desigual y combinada del todo con cada una de sus partes.

8. Del igual modo, Kosik (1967:11) dice lo mismo, pero con un temor que prueba que la separación y la reunión, después, sobre la ilusión primera que causa aquella, ha sido el negocio de los pensadores de toda la vida. "Si la apariencia fenoménica y la esencia de las cosas coincidieran totalmente, la ciencia y la filosofía serían superfluas". Y exactamente es lo que sucede ya con la episteme y la doxa; el ser y los entes; el samsara y el nirvana. La definición se ajusta al empleo masivo de la tecnología por parte de millones de usuarios comunes.

9. Zorba "El griego", posiblemente sirva de ejemplo, al reunir en sí mismo, al nirvana y al samsara, tal como lo miró Nagarjuna. Era tan común y corriente, y a la vez, sin saberlo, tan sabio, ese hombre, que sólo necesitábamos bailar con él para averiguarlo.

10. Medir, calcular y juzgar es comparar y, esto último, es desear, desde lo que ya se es hacia lo que se debe ser.

11. Si Derrida, en De la Gramatología, hubiera deconstruido los cinco textos básicos de las culturas humanas a partir de los cuales todos los demás libros son copias (Bagahvad Gita, Tao Te King, Las Cuatro Nobles Verdades, El Corán y La Biblia) en vez de estar polemizando contra Lévi-Strauss, al final, se hubiera visto escribiendo contra sí mismo y preparándose para desaparecer o fundirse con su objeto.

12. El pragmatismo y la hermenéutica no andan muy lejos de decir cosas parecidas (Vattimo, 1991; 2010) 